\title{
E-Learning and Constructivism: From Theory to Application
}

\author{
Alex Koohang, Liz Riley, and Terry Smith \\ Macon State College, Macon, Georgia, USA
}

\begin{abstract}
Alex.Koohang@MaconState.edu; Liz.Riley@MaconState.edu; Terry.Smith1@MaconState.edu
\end{abstract}

\author{
Jeanne Schreurs \\ Hasselt University, Belgium \\ jeanne.schreurs@uhasselt.be
}

\begin{abstract}
This paper presents a learner-centered model for designing e-learning assignments/activities within e-learning environments. The model is based on constructivism learning theory. The model includes two categories - the learning design elements (comprised of fundamental design elements and collaborative elements) and the learning assessment elements (self-assessment, team assessment, and facilitator's assessment). The application of the model is shown through various working examples. A factual situation using the model within an e-learning course is presented to further demonstrate the application of the model in an actual e-learning environment.
\end{abstract}

Keywords: E-learning, constructivism, e-learning design, collaborative learning, assessment

\section{Introduction}

While e-learning is becoming increasingly popular among students, the issue of learning in elearning environments must be given a thorough attention. In other words, ensuring learning takes place through e-learning courses must be a priority in designing instruction for e-learning courses.

Research agrees that constructivism learning theory, which focuses on knowledge construction based on learner's previous experience, is a good fit for e-learning because it ensures learning among learners (Harman \& Koohang, 2005; Hung, 2001; Hung \& Nichani, 2001; Koohang \& Harman, 2005).

The purpose of this paper is to 1) describe a learner-centered model for designing e-learning as-

Material published as part of this publication, either on-line or in print, is copyrighted by the Informing Science Institute. Permission to make digital or paper copy of part or all of these works for personal or classroom use is granted without fee provided that the copies are not made or distributed for profit or commercial advantage AND that copies 1) bear this notice in full and 2) give the full citation on the first page. It is permissible to abstract these works so long as credit is given. To copy in all other cases or to republish or to post on a server or to redistribute to lists requires specific permission and payment of a fee. Contact Publisher@InformingScience.org to request redistribution permission. signments/activities in e-learning environments, which is based on constructivism learning theory, and 2) show the application of the learner-centered model in e-learning environments. This paper is organized as follows.

First, a brief explanation of the elearning and e-learning design is presented. Secondly, the constructivism learning theory is explained based on 
previous research. The discussion then turns to describing the learner-centered model for designing e-learning assignments/activities based on constructivism learning theory. Examples are provided and described to show the application of the model within e-learning environments and a short factual situation is presented using the model in an undergraduate systems analysis and design course, which further illustrates the application of the model in an actual e-learning envi-

ronment. Conclusion and recommendations for future research on the use of the learner-centered model in e-learning environments complete the paper.

\section{E-Learning and E-Learning Design}

E-learning or Distance Education is progressively being chosen among students in the higher education institutions. A report in 2006 by Allen and Seaman indicated that 3.2 million students in the USA, mostly undergraduates, were taking at least one online course in fall 2005 term. A recent report by Allen and Seaman (2008) indicated that online enrollments have been growing significantly faster than the higher education enrollments in general. The report outlined the following:

- Almost 3.5 million students were taking at least one online course during the fall 2006 term; a nearly 10 percent increase over the number reported the previous year.

- The 9.7 percent growth rate for online enrollments far exceeds the 1.5 percent growth of the overall higher education student population.

- Nearly twenty percent of all U.S. higher education students were taking at least one online course in the fall of 2006.

Koohang and Harman (2005) stated that "e-learning is the delivery of education (all activities relevant to instructing, teaching, and learning) through various electronic media." Koohang (2004) stated that appropriate instructional design that includes learning theories and principles is critical to the success of e-leaning.

Broderick (2001, par. 1) stated that "Instructional Design is the art and science of creating an instructional environment and materials that will bring the learner from the state of not being able to accomplish certain tasks to the state of being able to accomplish those tasks." Instructional design has always relied on instructional models, namely behaviorism, cognitivism, humanism, and constructivism. Much of the attention in the last two decades has been shifted to constructivism because it promotes active learning through knowledge construction (Gagne, Briggs, \& Wager, 1992).

The critical issue of including learning theories in e-learning instruction design has consistently been reported in the literature (Egbert \& Thomas, 2001; Koohang \& Durante, 2003; Pimentel, 1999; Randall, 2001). The literature has also consistently documented that constructivism learning theory is an appropriate match for e-learning design (Harman \& Koohang, 2005; Hung, 2001; Hung \& Nichani, 2001; Koohang \& Harman, 2005).

\section{What is Constructivism?}

Entrenched in learning theories advanced by Dewey (1916), Piaget (1972), Vygotsky (1978) and Bruner (1990), constructivism learning theory is defined as active construction of new knowledge based on a learner's prior experience. Woolfolk (1993, p. 485) states the following:

... The key idea is that students actively construct their own knowledge: the mind of the student mediates input from the outside world to determine what the student will learn. Learning is active mental work, not passive reception of teaching. 
Honebein (1996) advanced a set of goals that aid the design of constructivism in learning settings. These goals are to:

- "Provide experience with the knowledge construction process;

- Provide experience in and appreciation for multiple perspectives;

- Embed learning in realistic and relevant contexts;

- Encourage ownership and voice in the learning process;

- Embed learning in social experience;

- Encourage the use of multiple modes of representation; and

- Encourage self-awareness in the knowledge construction process." (Honebein, 1996 p. 11)

Murphy (1997) presented an excellent summary of characteristics of constructivism learning theory based on a comprehensive review of literature. These characteristics are as follows:

1. "Multiple perspectives and representations of concepts and content are presented and encouraged.

2. Goals and objectives are derived by the student or in negotiation with the teacher or system.

3. Teachers serve in the role of guides, monitors, coaches, tutors and facilitators.

4. Activities, opportunities, tools and environments are provided to encourage metacognition, self-analysis -regulation, -reflection \& -awareness.

5. The student plays a central role in mediating and controlling learning.

6. Learning situations, environments, skills, content and tasks are relevant, realistic, authentic and represent the natural complexities of the 'real world'.

7. Primary sources of data are used in order to ensure authenticity and real-world complexity.

8. Knowledge construction and not reproduction is emphasized.

9. This construction takes place in individual contexts and through social negotiation, collaboration and experience.

10. The learner's previous knowledge constructions, beliefs and attitudes are considered in the knowledge construction process.

11. Problem-solving, higher-order thinking skills and deep understanding are emphasized.

12. Errors provide the opportunity for insight into students' previous knowledge constructions.

13. Exploration is a favoured approach in order to encourage students to seek knowledge independently and to manage the pursuit of their goals.

14. Learners are provided with the opportunity for apprenticeship learning in which there is an increasing complexity of tasks, skills and knowledge acquisition.

15. Knowledge complexity is reflected in an emphasis on conceptual interrelatedness and interdisciplinary learning. 
16. Collaborative and cooperative learning are favoured in order to expose the learner to alternative viewpoints.

17. Scaffolding is facilitated to help students perform just beyond the limits of their ability.

18. Assessment is authentic and interwoven with teaching." (Murphy 1997)

\section{The Model}

Koohang (2009) advanced a model based on constructivism learning theory in e-learning environments. The model includes three categories for elements of Constructivism:

1. The Design of Learning Activities

2. Learning Assessment

3. Instructor's Roles

The design of learning activities included collaboration, cooperation, multiple perspectives, real world examples, scaffolding, self-reflection, multiple representations of ideas, and social negotiation. The learning assessment elements consisted of instructor assessment, collaborative assessment, and self-assessment. The instructor's roles were coaching, guiding, mentoring, acknowledging, providing feedback, and assessing student learning.

The present study adapted the model by Koohang (2009) to include all essential elements of constructivism and better categorizes the elements of constructivism for designing learning assignments/activities in e-learning environments.

Figure 1 depicts the new model. The model is comprised of two categories: the learning design elements and learning assessment elements. The learning design elements include fundamental design elements and collaborative design elements. The fundamental design elements are essential for designing learning activities. They include the following nine elements:

1. Conceptual interrelatedness and interdisciplinary learning

2. Exploration

3. Higher-order thinking skills

4. Learner's driven goals and objectives

5. Learner's own previous experiences

6. Learner's self-mediating and control of learning

7. Learner's self-reflection

8. Real world and relevant examples

9. Scaffolding that can be used to make learners think above and beyond what they normally know

The collaborative design elements for learning activities include the following five elements:

1. Learners' collaboration

2. Learners' cooperation

3. Learners' multiple perspectives

4. Learners' multiple representations of content/idea/concept

5. Social negotiation among learners 
Learning assessment elements are integral to the learner-centered model for designing e-learning assignments/activities. Erwin (1991) defines assessment as “...the systematic basis for making inferences about the learning and development of students. More specifically, assessment is the process of defining, selecting, designing, collecting, analyzing, interpreting, and using information to increase students' learning and development."

The learning assessment elements of the learner-centered model for designing e-learning assignments/activities include the following three elements:

1. Individual self-assessment

2. Team collaborative assessment

3. The facilitator's assessment

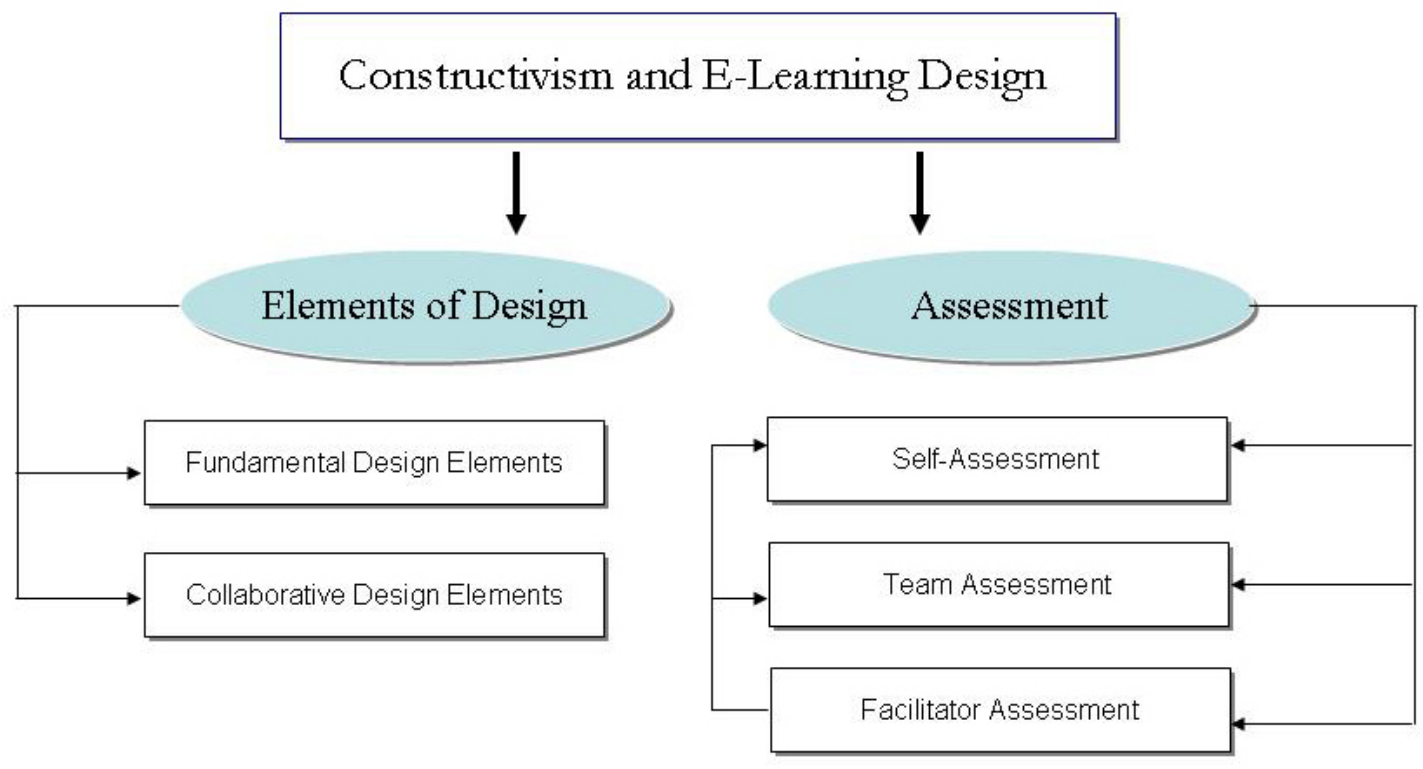

Figure 1: Constructivism Elements \& E-Learning Design of Learning Activities

The aim of the learner-centered model for designing e-learning assignments/activities is to encourage learners to actively construct new knowledge. The design of activities normally begins with presenting a real-world situation. The real-world situation can be either provided by the facilitator or the facilitator may ask learners to search for a real-world situation. Learners are encouraged to develop their own goals and objectives in solving problems. At this time, the design strategy is to encourage exploration and learner's control of the learning. Learners will begin to be responsible for their learning. Once the real-world situation is presented, the learner's own previous experience and knowledge are embedded into the design of the activity.

The learner is asked to apply his or her own experience and/or knowledge in the situation. The previous experience can be job-related, knowledge from materials presented in the current course or previous courses, and/or personal experience. This also encourages interrelatedness and interdisciplinary learning.

Next, the learner's self-reflection and scaffolding elements are integrated into the design of the activity. The learner is asked to reflect on what he or she has learned, which will encourage the learner to be responsible for his or her own learning. The learner should be required to give justification for his or her answers, and scaffolding becomes a vital learning means. The learner should also be required to go beyond what he or she has learned. 
The learners are now placed in small and/or large teams to collaboratively construct knowledge. Multiple perspectives are presented, covering various content, ideas, and concepts. Social negotiation among learners is encouraged.

Three various assessments may be designed into the activity: self assessment (learner is assessing his or her own work), team assessment (learners are assessing each others' works) and facilitator assessment (the facilitator is assessing individual and team works). The facilitator values the learner's expressed thoughts and reflections. The facilitator takes the role of a coach, mentor, and/or guide to provide feedback to learners.

\section{The Application of the Model}

In this section various examples are presented to demonstrate the application of the learnercentered model for designing e-learning assignments/activities within the e-learning environments. These examples are from Information Technology and Business fields. They could, however; be adapted and used for other fields of study. Explanation is provided for each example to validate the use of the model.

\section{Example: Knowledge Management Assignment}

\section{Assignment overview}

This is a generic two part, two-week assignment on the knowledge management (KM) topic. Part one is completed at the end of the first week and part two is completed at the end of the second week. This assignment includes both individual and collaborative activities.

\section{The assignment - Student instruction}

Part 1 - Visit the online university's library and search for a real-world example of how an online company uses knowledge management (KM) to manage and improve its key performance indicators such as page views, server load, network traffic, and transactions per second. Each student will do the following:

1. Write a brief explanation of his/her findings ( $150-200$ words).

2. Based on his/her previous knowledge and experience including the course materials and the textbook, the student is to write a 300 to 400 -word-essay regarding his/her thoughts and reactions on how the company is utilizing $\mathrm{KM}$ technologies and methodologies to manage and improve key performance indicators.

Part 2 - Students are formed into various teams of 3 to 5 individuals. Each team will read all their colleagues' postings from part 1 . Each team will choose three of their colleagues' postings that they agree to evaluate and assess. The team will write a $400-500$-word essay that includes the following:

1. A brief explanation of the three postings.

2. What the team has identified, analyzed, and interpreted from the postings that may have contributed to their learning.

3. The team's thoughts, advice, reaction, and/or viewpoints about the postings.

\section{Explanation of the assignment}

Part 1 of this example begins with exploration. Each individual is to choose a real-world example of how an online company uses KM to manage and improve its key performance indicators such 
as page views, server load, network traffic, and transactions per second. The conceptual interrelatedness and interdisciplinary learning will be evident when each individual is exposed to various aspects of KM. Each individual presents his or her reaction based on his or her previous knowledge, experience, and/or perception. Scaffolding takes place by allowing each student to express his or her viewpoints/opinion regarding the issues.

Part 2 of this example is to promote collaborative learning among learners. Each team of 3 to 5 members will, through cooperation, representation of viewpoints, perspectives, and negotiation, collaboratively evaluate and assess their colleagues' postings. At all times, the instructor acts as a coach, a mentor, and/or a guide to provide feedback to learners.

\section{Example: Human Computer Interaction (HCl) Assignment}

\section{Assignment overview}

This assignment is seven weeks in duration. The assignment is an HCI journal activity and it is among other HCI assignments during the course. It requires students to keep a journal for the first six weeks and provide a summary of their report.

\section{The assignment - Student instruction}

Each student is to keep a human-computer interface (HCI) journal for the next six weeks. The journal will contain your daily experiences using devices and products with human-computer interfaces. It will also include your observations of the $\mathrm{HCI}$ issues that you encounter. This is an opportunity for you to observe and reflect on how HCI issues permeate what we do and how others are affected by design and use of human-computer interfaces.

Your job is to write a 15 page report that includes:

1. A chronological log of dates that provide a clear narrative of your observations/experiences in recognizing $\mathrm{HCI}$ in the digital environment.

2. Entries that contain a description of your experience, how usable the interface was, and what changes you would make (if any) to improve the interface.

3. About one to two pages at the end, summarizing what you've learned from this experience and how it relates to your own previous knowledge of human-computer interfaces (gained from the course materials, the textbook, the online discussions, and your personal experiences).

This paper will be turned in at the end of the sixth week and you will be graded individually for this paper.

While observing and documenting your HCI experiences you will also have the following assignments:

On the first day of Week 3 you are required to post, on the discussion board, one of your entries you have documented for your final paper. This entry will include a description of your experience, how usable the interface was and what changes you would make for improvement.

During Week 3 everyone must read all classmates' postings and respond (providing reactions and/or viewpoints about the experience) to any three postings. The instructor will read all postings and provide feedback.

At the end of the six week period, students are required to post, on the discussion board, a summary of what they have learned during this assignment and how their experiences relate to their 
previous knowledge of human-computer interfaces (gained from the course materials, the textbook, the online discussions, and your personal experiences)

During week 7 everyone must read all classmates' postings and respond (providing reactions and/or viewpoints about the experience) to any three postings. The instructor will read all postings and provide feedback.

\section{Explanation of the assignment}

In this example students document their experiences of HCI. Students reflect on each experience and identify the changes that could be made to improve the interface. They base their recommendations on previous knowledge obtained from coursework, the textbook, online discussion about interface usability, and experiences with other interfaces. The assignment encourages scaffolding because the students are required to articulate what they have experienced and reflect on their activity. Active participation on the discussion board encourages collaborative learning among students. It encourages multiple representations of ideas and viewpoints. For all activities, the instructor provides feedback on the assessment to learners.

\section{Example: IT Project Management Assignment}

\section{Assignment overview}

This is a research-based assignment in the area of IT project management. It is three weeks in duration and includes both collaborative and individual activities.

\section{The assignment - Student instruction}

Part 1 - Students are formed into various teams of three to five members. For a two week period, each team will be responsible for researching the impact of the Sarbanes-Oxley Act of 2002 on IT project management, using the Internet and the school's online library. Each team will write (and post on the discussion board at the end of Week 2) a 500-750-word essay that will include:

1. Examples and explanations of how the act impacted IT project planning, execution, and control.

2. Findings about how the act has changed the way IT projects are led and managed to meet the mandates and requirements of the act.

3. Thoughts about how the act has impacted the value of projects and project management practices to the organization.

4. An explanation of the relationship between the emergence of the Project Management Office and the IT governance requirements contained in the act.

Part 2 - Students are to read all the postings during Week 3. Each student is required to write a 250-300 word essay about two postings (not including their team's posting). The essay must include each individual's reaction and/or viewpoints about what he/she has learned from teams' postings. In addition each student will write a 200 word-essay, describing their experience with collaborative team learning.

\section{Explanation of the assignment}

In this example, each team begins with exploration by using the Internet and the school's online library. The collaborative exercise requires the team to find information using real-world examples of how the act has changed IT project management. The group exercise requires collaboration, cooperation, social negotiation, and sharing of ideas among students. Scaffolding is a natu- 
ral result of this group exercise. The individual assignment in part 2 of this example will give an opportunity to each student to broaden their own knowledge thus promoting their learning. For all activities, the instructor provides feedback and assessment to learners.

\section{Example: Corporate Performance Management Assignment}

\section{Assignment overview}

This assignment is a course project in a graduate course in strategic information management. The project is on corporate performance management (CPM) and how information systems can support the CPM in small and medium enterprises (SME). The assignment is 10 weeks in duration and includes three parts. Part one includes the theoretical concepts and methodology of CPM. Part two demonstrates and reinforces the CPM in small and medium enterprises. Part three includes an information system - balanced scorecard (BSC) to support the selection process of CPM.

\section{The assignment - Student instruction}

Part 1 - Theoretical concepts and methodology of CPM (Week 1-3)

Each student will visit the online university's library and search for an article that includes a realworld example of a company that utilizes corporate performance management (CPM). Each student will write a 700 - 800-word essay that contains the following:

1. A summary of the article's findings including the company's strategic benefits of implementing CPM.

2. Explanation of your thoughts and reactions about how the company approaches the identification of key performance indicators with their measurement models and the monitoring the performance of the company based on those measurements. Your thoughts and reactions must be justified by including your own previous experience, knowledge, and/or perception.

This assignment will be submitted at the end of Week 3 .

Part 2 - CPM in SME (Week 4)

1. Students must read all their colleagues' postings. Students will take notes as they read their colleagues' postings. Students are to form questions based on their readings to be asked from a CPM expert.

2. The instructor will schedule an asynchronous session with a CPM expert within a real company to answer students' questions. All the communication will take place on the discussion board.

3. Based on colleagues' postings and the discussion between students and the CPM expert, each student will write a 500-600-word essay about his/her thoughts, reaction, and/or viewpoints regarding CPM in small and medium sized enterprises (SMEs). This assignment will be submitted at the end of Week 4 .

Part 3 - Information System supporting CPM: BSC (Week 5 - 10)

1. Students will participate in a demonstration session that includes a real-world best practice CPM in a real company. This will be scheduled by the instructor.

2. The instructor will then schedule an asynchronous Q\&A session with an expert within the company to further explore and examine the CPM within the company. All the communication will take place asynchronously on the discussion board. 
3. Students will develop a set of quality criteria (in a form of a 15-page, single-spaced paper) that can be used in the selection process of CPM using a balanced scorecard (BSC) system based on the experience they have acquired from the demonstration session and the Q\&A interaction with the expert from the company. The paper will be submitted at the end of the tenth week.

\section{Explanation of the assignment}

This assignment uses virtually all the constructivism design elements in the learner-centered model for designing e-learning assignments/activities advanced in this paper. The activities are both individual and collaborative. This assignment requires high level of interaction among students, expert consultants and the professor. At all times instructor provides feedback to students and assesses their learning.

\section{Example: Programming Assignment}

\section{Assignment overview}

This assignment is 3 weeks in duration. The class will be divided into small teams of three to five students. Individuals on each team will search the Internet for a simple mortgage calculator and share a description of the calculator on the team's assigned discussion board. Then, as a group, the team will create a Java program with functionality similar to what was found in the calculator on the Internet. This example is appropriate for students in a first semester programming course. While this particular assignment is for the Java programming language, it could easily be adapted and/or altered to fit any programming language.

\section{The assignment - Student instructions}

Step 1: Use the Internet to find a Web site that includes a mortgage payment calculator. Run the calculator with a set of realistic values. This includes a current mortgage interest rate which you will have to look up on a bank's Web site. On your team's discussion board post the following:

- a link to this calculator

- a description of the values that you input and why you chose those values

- a description of the value(s) that the calculator generated

Step 2: As a group, create a Java program that is a mortgage calculator. All codes and discussion should be posted on the discussion board. It is expected that every individual will contribute to this program and its discussion. The program should allow the user to type in the same kind of values (loan amount, interest, etc.) that you found in any calculators on the Internet. The formula for calculating the payment is as follows:

(amount of loan * monthly Interest rate) /(1 - Math.pow $(1 / 1+$ monthly interest rate), number of payments))

The team's last entry in the discussion board should be the complete program.

Step 3: Once the project is complete, each student will submit the following paragraphs:

- A reflection on the benefits and obstacles to programming in a team environment. Comment on how well you contributed to the programming process. A reflection on what you would have done differently if you could do this assignment again as a team (200 to 300 words).

- Write at least three sentences describing the input that each team member provided for 
this assignment. In other word, if you have four teammates, you will be writing twelve sentences.

- There are many applications in which data are input, a math calculation takes place, and output is provided. These applications are found on banking sites, exercise and fitness sites, travel sites, etc. Describe in your own words, a similar program that you could write in Java to create one of these types of applications. Describe the inputs, outputs, and calculations that will be needed in the program (300-400 words).

\section{Explanation of the assignment}

This example uses many of the fundamental design elements of the learner-centered model for designing e-learning assignments/activities advanced in this paper. The interdisciplinary learning element is implemented by using a mortgage calculator in a Java program. This combines the concepts of finance from the business discipline and programming from the computer science discipline. This example also supports the element of real world/relevant examples because most students have either purchased or have considered purchasing a house or some other large item that requires payments. The previous experiences element is included because the learners would have previously been introduced to the necessary fundamentals of Java programming. The selfreflection element is supported in Step 3 of this example as learners are asked to consider how well they did in the team programming part of this example and what they would do differently. They are also asked to think beyond this programming project to try to identify similar applications. This last task supports the scaffolding element.

This example includes many of the collaborative design elements. The group work required in Step 2 of this project requires collaboration and cooperation amongst students. Negotiation will have to take place as students determine which lines of code to include in their final program. Students are given the opportunity to look at this problem from the perspective of a user as well as from the perspective of the programmer creating a mortgage calculator.

All three assessment elements are included in this project. Each individual must evaluate how well they thought he or she contributed to the programming process. The individuals are then given the opportunity to evaluate their teammates. Lastly, the instructor will evaluate the individual's work in steps 1 and 3 as well as the group's work in step 2.

\section{Example: Research Assignment}

\section{Assignment overview}

This assignment is 14 weeks in duration. The class will be divided into teams which will be required to research a recently introduced technology. The team will then find a company listed on the New York Stock Exchange (NYSE) for which they think this technology is appropriate. Lastly, they will present information about the new technology and how the chosen Company could use this technology. This presentation will be for their classmates who will be role-playing as investment bankers deciding whether to lend the company money for the technology.

\section{The assignment - Student instructions}

Week One - Technology essay: On the class discussion board post a 250 - 300-word essay describing an emerging, important technology that has "appeared" in the last 2 years. Please include an explanation of why you think this technology is important. You may not duplicate any technology posted by other students.

Week Two - Vote on technologies: Read all your classmates' technology essays. Chose and post on the discussion board what you think are the six most important technologies. 
Weeks Three through Eight - Teamwork Project: You will be divided into teams. Your team will be assigned to one of the technologies. The team will then need to thoroughly research the technology. Next, the team will find an organization on the NYSE that can benefit from the use of this technology. Once the team has chosen its organization, the team will complete the following two tasks:

\section{Task 1: A Research paper}

Write a 3000 word paper (approximately 10 pages not including cover pages, bibliography, etc.) that includes the following:

- A complete explanation of the assigned technology including its current state and where it will be in 3 to 5 years.

- A description of the company chosen from the New York Stock Exchange listing.

- An analysis of how this company can use this technology for profit. This section should take into account what products the company currently produces; how the technology fits into or extends that product-base; and what costs are associated with the new technology. Some imagination can be used in this part as long as the application of the technology is plausible and thoroughly explained. For example, one would not expect Ford Motors to invest in a technology that would be used for higher education. That's not logical or plausible.

Note: The target audience for this paper is a chief information officer (CIO) of the assigned company. The technology should be described in a way that he/she can understand. The CIO should also thoroughly understand how the technology would be of value to the company.

\section{Task 2: A PowerPoint presentation with audio for your classmates}

The audience for this presentation is your classmates who will be role-playing as bankers. These "bankers" are attempting to determine whether to loan money for this technology to your NYSE organization. Your presentation should give the "bankers" a clear understanding of the corporation, the technology, and why this corporation should be investing in this technology. The presentation should last approximately 20 - 30 minutes.

Both Tasks 1 and 2 are due at the end of week 8 .

Weeks Nine through Thirteen - Presentations: Your team will be assigned a week in which to post its presentation on the discussion board. During this week, classmates are allowed to post questions and the team will be expected to respond to these questions. Reponses should be up within 48 hours of the question being posted.

When it is not your team's week to present, you will be serving as a "banker". "Bankers" are expected to view each presentation and post at least one question on the discussion board. Your question(s) should help you determine whether to lend money or not. The Presenting team is expected to answer posted questions within 48 hours. You may submit questions for three days after the presentation. Seven days after the presentation, you must turn in to the instructor a two page paper (approximately 600 words) that indicates whether you have chosen to lend money to the company and why.

Week Fourteen - Reflection Paper: At the end of Week 14, each student will submit a paper (500 to 600 words) describing the following:

- their contribution to their teams' work

- a description of each of their teammate's contribution

- what they learned that they didn't know prior to this activity 


\section{Explanation of the assignment}

This example incorporates several of the fundamental design elements of the learner-centered model for designing e-learning assignments/activities advanced in this paper. The interdisciplinary learning element is included in the team paper, presentation, and banker's opinion.

These parts of the example will, at the very least, incorporate concepts from information technology as well as business. The exploration element is included in the students' first assignment that requires them to find a recently introduced technology. The exploration element is also included in this example as the students search for a company on the NYSE. Higher order thinking skills (analysis, evaluation, and synthesis) are included in the new technology essay, the research paper, the presentation, and the banker's opinion. The research paper and presentation support the learner driven goals and objectives element. In these two components students choose what parts of the technology to explore further and also search through companies on the NYSE. The student's previous experience is incorporated in the new technology essay, the research paper, and the banker's opinion. The students will have control of their learning as they research their technology and the corporation that will use the technology. Students will have the opportunity for self-reflection in their banker's opinion essay and their final self-reflection paper. The new technology essay, the research paper, the presentation, and the banker's opinion essay all bring into play the elements of the real-world experience. Lastly, scaffolding takes place as the students build their research paper and their banker's opinion essay.

In this example, learner's collaboration, cooperation, multiple perspectives, and social negotiation will all take place within the process of the team creating their research paper and presentation. Multiple perspectives may also be included in the first task where each person describes an important technology. The research paper and the presentation provide the students with the opportunity to represent their information and ideas in multiple formats to multiple audiences.

All three assessment elements are included in this project. The individual self assessment occurs in the final reflection paper. Collaborative assessment takes place at two points in this example. One part of the reflection paper assessed each teammate's contribution to the project. The banker's opinion write-up also can be used as an assessment tool in that it provides some insight into how well each team presented their arguments for using the new technology. Lastly, instructor assessment comes into play in the individual's new technology essay, the team's research paper and presentation; the banker's opinion paper, and the final reflection paper.

\section{A Factual Situation}

In this section, a short factual situation is presented using the learner-centered model for designing e-learning assignments/activities that is advanced in this paper in an undergraduate systems analysis and design course. The course was taught by one of authors of this paper. This case/project based course was 15 weeks in duration. There were eight chapters to be covered. The weekly assignments generally included chapter analysis (individual \& group assignments), and case analysis/case comparison (individual $\&$ group assignments). The course also included a final group case/project based assignment.

Part one of the chapter analysis was an individual assignment. Students were required to read two chapters and the notes that were associated with the chapters. The assignment required each individual to write a 400-word essay about their reactions and thoughts on four topics that interested them most (two topics from each chapter). They were asked to be clear, concise, and persuasive in expressing their reactions and thoughts. Applying and/or justifying the topics of interest to various situations/circumstances were strongly encouraged.

Part two of the chapter analysis occurred a week after part one was posted by all students and graded by the professor. This part was a collaborative assignment among all students. The as- 
signment asked students to read all their colleagues' postings from part one of chapter analysis assignment from previous week. Students were then to comment on two or more of their colleagues' postings. They were asked to share their opinions, thoughts, and/or reactions regarding the postings.

The weekly case analysis was a real-world example that related to the subjects covered in the textbook. Students were asked to thoroughly read an assigned case and provide answers to a few questions. Students were required to 1) base their answers on textbook and notes and 2) express how they would approach the problem based on their own previous experience, knowledge, and/or perception.

The case comparison assignment would occur a week after everyone had posted his or her answers to the case analysis assignment. The case comparison assignment required each student to compare his or her answers to the ones the professor had provided.

The final team assignment was a collaborative effort to reinforce and apply the knowledge learned throughout the course. Students were divided into teams of four to five individuals. A real-world case study about an existing organization's information system was provided to each team. Each team was asked to focus on the challenges of rebuilding and improving the organization's information system and to provide their findings and recommendations. In formulating their findings and recommendations, each team was asked to include their own previous experiences and knowledge.

After the final projects were submitted, students were asked to write (and submit to the instructor via the online courseware) a paragraph providing feedback about their learning experience in the course. The feedback did not carry any points/grades and the instructor did not look at them until the final grades were submitted. Students were told that their feedback was independent of the course/instructor evaluation and that their participation was absolutely voluntarily. Because the feedback results were going to be used in this study, the IRB approval was sought and granted. All students who provided feedback about the course were 18 years or older. They were assured confidentiality regarding their responses. Below is a list of excerpts from the students' feedback.

- "Quite a few times, in this course, people would take a completely different train of thought ... we discovered ... different opinions based on our experiences ... we gained experience with our peers by discussing the different viewpoints."

- “... the activities, etc. helped to sort of liven up the text we read and also helped in making it more understandable by putting it to the test and using it in a real-life situation."

- “... by having the ability to see what other classmates came up with for their case analysis, we were also gaining various viewpoints and perceptions. I really think I gained the most from seeing what others did and how they tackled each task, especially because everyone's answers were unique."

- “... it was interesting to see everyone else's interpretation. The "real world" case studies helped me to solidify my knowledge."

- "The discussions and class activities where informative and they help me to understand the processes that you need to follow in order to go through the SDLC. Having to read the other student's activities was useful as well. It gives you a base line to see how the activities were interpreted by others and gives you a sense as to whether or not you understood the activity. "

- "The chapter essays provided a good opportunity to learn from each other by showing some real life examples of the topics. They also provided a good review of main chapter ideas. There always seemed to be a wide variety of topics and examples shared." 
- "Being able to see the answers other students were reaching for the cases and then sharing our thoughts about all of the answers submitted in general was a useful way for me to absorb all of the information presented."

- "It was nice to see the many interpretations from the same basic information and realize that there isn't always one concrete way to accomplish a specific task."

- "I really enjoyed the format of this course and the interactions that we had."

- 'I liked that I was able to read the other students' answers to the problems. It gave me perspective on my own answers."

- "Case comparisons helped me to better understand my mistakes as well as my strong suits."

- “... this class brought the concepts of many of my other classes together into a more "real world," apply-what-you-know kind of environment."

- "By comparing what I came up with, what the instructor gave as the correct answer, and what everyone else wrote down, I have been able to see that this subject is not as clear and dry cut as I thought. There are many ways to be creative with the information we have been given--we must only learn the proper techniques before applying them in our own creative ways."

- "Reading others case responses allowed me to see different perspectives in action which in turn allowed me to evaluate my perspective and improve upon or reinforce the perspective I had."

- "I enjoy putting things that you learn into practice."

- "I learned a lot especially each week when we had to do the case studies. I thought they were a lot of fun. Every one presented a new challenge and I really enjoyed that part of the class."

- 'I also really enjoyed reading my fellow students' postings each week. I think that the weekly postings by my fellow students were a great a learning tool as well. I think that this interaction is a great way to further understanding of the topics in the class."

- "My favorite activity in this course was the case comparisons. They gave me insight into how my fellow classmates thought and they were a very good check for my mode of thinking."

- "My learning experience in the class was enhanced by the discussion with my peers."

- "The case assignments provided real world practical experience with the subject. The case comparisons were especially helpful in being able to evaluate my own understanding compared to the professor and fellow students."

- "I know I found myself noticing things in other student's submissions that brought some things to my attention that I had overlooked."

- 'By reading my classmates' assignments, I discovered what was missing in my assignment."

- "I definitely learned from the discussions. I think they forced you to think critically."

- "I liked comparing our answers because I learned a lot from my classmates. It helped open up my eyes so-to-speak on topics I was having a hard time understanding." 
- 'Reading and comparing my classmates' work with my own was beneficial, but more in the sense that it made me feel more confident that I was on the right track."

From the excerpts above, we have categorized the students' feedback (words, phrases, and/or sentences) into the three parts of the learner-centered model for designing e-learning assignments/activities advanced in this paper: fundamental design elements, collaborative design element, and learning assessment design elements. The fundamental design elements include the following:

- "discovered ... different opinions based on our experiences"

- "The "real world" case studies" and "real life examples"

- "a wide variety of topics and examples shared"

- "apply-what-you-know kind of environment"

- "sharing our thoughts"

- 'other student's submissions that brought some things to my attention that I had overlooked"

- "Every one presented a new challenge"

- "insight into how my fellow classmates thought and ...very good check for my mode of thinking"

- 'By reading my classmates' assignments, I discovered what was missing in my assignment"

- "think critically"

- “open up my eyes so-to-speak on topics I was having a hard time understanding"

The collaborative design elements include the following:

- "gained experience with our peers by discussing the different viewpoints"

- "gaining various viewpoints and perceptions"

- "a base line to see how the activities were interpreted"

- "many interpretations"

- "the interactions"

- "different perspectives"

- "discussion with my peers"

The learning assessment design elements include the following:

- "perspective on my own answers"

- "better understand my mistakes as well as my strong suits"

- "evaluate my perspective and improve upon or reinforce the perspective I had"

- "putting things that you learn into practice"

- "evaluate my own understanding"

- "it made me feel more confident that I was on the right track" 
- "evaluate my own understanding compared to the professor and fellow students"

- "reading and comparing my classmates work with my own was beneficial"

As can be ascertained from the categories above, virtually all the constructivism elements within each part of the model advanced in this paper were present in students' feedback. It is notable to mention that students were asked to "provide feedback about their learning experience in the course". They were given no hint or instruction whatsoever about the use of the learner-centered model for designing e-learning assignments/activities throughout the course.

\section{Conclusion}

This paper presented a learner-centered model for designing e-learning assignments/activities based on constructivism learning theory within e-learning environments. The model includes three essential parts: fundamental design elements, collaborative design element, and learning assessment design elements. It requires active construction of knowledge by designing realworld assignments/activities. Through exploration, learners are encouraged to develop their own goals and objectives in solving problems. They are required to include and apply their own previous experience in solving problems. Interrelatedness and interdisciplinary learning, learner's self-reflection and scaffolding are necessary elements for the design of assignments/activities. Collaborative design elements such as multiple perspectives and social negotiation are designed into the assignments/activities using small and/or large teams to collaboratively construct knowledge. Self assessment, team assessment, and facilitator assessment are built into the design to continuously assess student learning.

A brief explanation of the e-learning and e-learning design was presented following a literature review regarding constructivism learning theory and its place in e-learning environments. Examples were provided to present the application of the model. In addition, a factual situation that used the model in an undergraduate course further illustrates the application of the model in an actual e-learning environment.

The factual situation indicated the advantage of the use of the model in e-leaning environments. Therefore, the authors recommend that the model presented in this study be followed carefully in designing e-leaning assignments/activities. Consequently, steps should be taken to further strengthen the model for its continuous improvement. The model also should be examined empirically to validate its soundness.

\section{References}

Allen, E., \& Seaman, J. (2006). Making the grade: Online education in the United States. The Sloan Consortium. Retrieved October 19, 2008 from http://www.sloanc.org/publications/survey/pdf/making the grade.pdf

Allen, E., \& Seaman, J. (2008). Online nation: Five years of growth in online learning. The Sloan Consortium. Retrieved October 19, 2008 from http://sloan-c.org/publications/survey/online nation

Broderick, C. (2001). What is instructional design? Retrieved October 19, 2008 from http://www.geocities.com/ok bcurt/whatisID.htm

Bruner, J. (1990). Acts of meaning. Cambridge, MA: Harvard University Press.

Dewey, J. (1916). How we think. Boston, MA: Houghton Mifflin Company.

Egbert, J., \& Thomas, M. (2001). The new frontier: A case study in applying instructional design for distance teacher education. Journal of Technology and Teacher Education, 9(3), 391-405.

Erwin, T. (1991). Assessing student learning and development. San Francisco: Jossey-Bass. 
Gagné, R., Briggs, L., \& Wager, W. (1992). Principles of instructional design (4th ed.). Fort Worth: Harcourt, Brace, Jovanovich College Publishers.

Harman, K., \& Koohang, A. (2005). Discussion board: A learning object. Interdisciplinary Journal of Knowledge \& Learning Objects, 1, 67-77. Retrieved from http://ijello.org/Volume1/v1p067077Harman.pdf

Honebein, P. (1996). Seven goals for the design of constructivist learning environments. In B. Wilson, Constructivist learning environments (pp. 17-24). New Jersey: Educational Technology Publications.

Hung, D. (2001). Design principles for web-based learning; implications for Vygotskian thought. Educational Technology, 41(3), 33-41.

Hung, D., \& Nichani, M. (2001). Constructivism and e-learning: balancing between the individual and social levels of cognition. Educational Technology, 41(2), 40-44.

Koohang, A. (2004). A study of users' perceptions toward e-learning courseware usability. International Journal on E-Learning, 3(2), 10-17.

Koohang, A. (2009). A learner-centered model for blended learning design. International Journal of Innovation and Learning, 6(1), 76-91.

Koohang, A., \& Durante, A. (2003). Learners' perceptions toward the Web-based distance learning activities/assignments portion of an undergraduate hybrid instructional model. Journal Information Technology Education, 2, 106-113. Retrieved September 21, 2005 from http://www.jite.org/documents/Vol2/v2p105-113-78.pdf

Koohang, A., \& Harman, K. (2005). Open source: A metaphor for e-learning. Informing Science: The International Journal of an Emerging Transdiscipline, 8, 75-86. Retrieved from http://inform.nu/Articles/Vol8/v8p075-086Kooh.pdf

Murphy, E. (1997). Constructivism: From philosophy to practice. Retrieved October 19, 2008 from http://www.cdli.ca/ elmurphy/emurphy/cle.html

Piaget, J. (1972). The psychology of the child. New York: Basic Books.

Pimentel, J. (1999). Design of net-learning systems based on experiential learning. JALN, 3(2). Retrieved April 30, 2003 from http://www.aln.org/publications/jaln/v3n2/v3n2 pimentel.asp

Randall, B. (2001). Effective Web design and core communication issues: The missing components in Web-based distance education. Journal of Educational Multimedia and Hypermedia, 4, 357-367.

Vygotsky, L. (1978). Mind in society. Cambridge, MA: Harvard University Press.

Woolfolk, A. E. (1993). Educational psychology. Boston: Allyn and Bacon.

\section{Biographies}

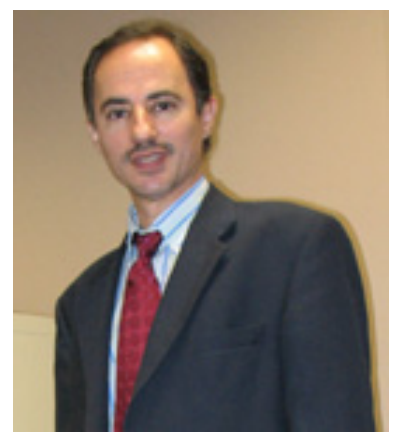

Alex Koohang is Peyton Anderson Eminent Scholar and Professor of Information Technology in the School of Information Technology at Macon State College. He is also the Dean of the School of Information Technology at Macon State College. Dr. Koohang has been involved in the development of online education, having initiated and administered some of the earliest asynchronous learning networks. His current research interests are in the areas of e-learning, learning objects, open education, open access, open source, and knowledge management. 


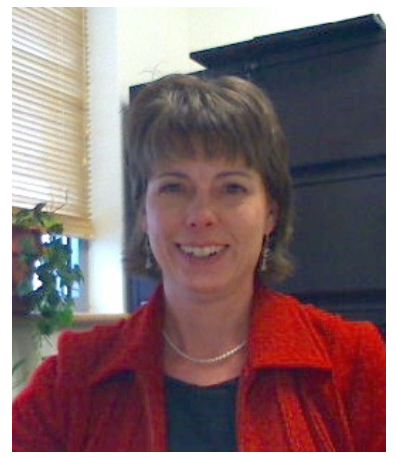

Elizabeth Riley is an Associate Professor in the School of Information Technology at Macon State College. She holds a M.B.A. from Georgia College and State University. She has 15 years experience as an Information Technology professional and has taught programming and web design courses for the last six years. She has an interest in the educational opportunities offered by virtual worlds.

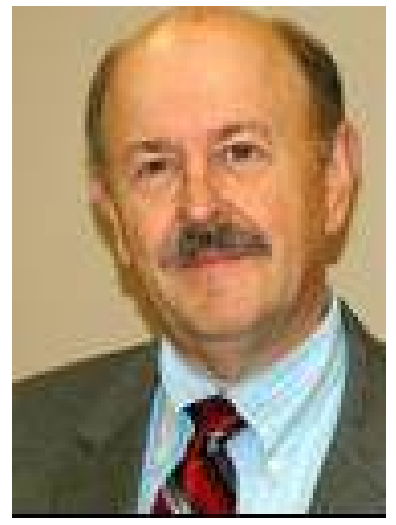

Terry Smith is an assistant professor in the School of Information Technology at Macon State College in Macon, Georgia. He holds a M.B.A. from the University of South Florida in Tampa, Florida, and a Ph.D. in Information Systems from Nova Southeastern University in Ft. Lauderdale, Florida. His research interests include human computer interaction, Web and Internet technologies, E-business, Ecommerce, and E-government.

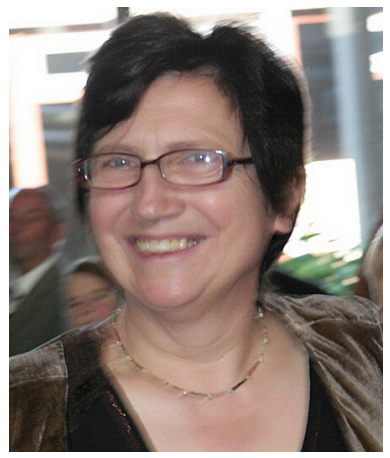

Jeanne Schreurs is a professor of Business Informatics - the Faculty of Economic Sciences - in the Department of Business Informatics at Hasselt University, Belgium. She teaches courses in information management, ICT management, strategic information management, ebusiness strategy and Business Information Systems. Her research is in the broad domain of knowledge management, e-learning (organisation of learning, content, presentation of learning content) and Management Information systems (Total Quality Management, Corporate Performance Management, ICT Risk and Security Management). 